\title{
Stabilitas Zeolit HY Hidrofobik terhadap Uji Hot Liquid Water (HLW)
}

\author{
The Stability of HY Hydrophobic Zeolites against Hot Liquid Water (HLW)
}

\author{
Yuni Susanti*, Yeni Variyana \\ Departemen Teknik Kimia, Institut Teknologi dan Bisnis Muhammadiyah Banyuwangi, Jl. Diponegoro No.60 \\ Genteng, Banyuwangi 68465, Indonesia \\ *Email: ysusanti@itbmb.ac.id
}

\begin{abstract}
Abstrak
Pada dasarnya katalis zeolit tidak dapat digunakan untuk reaksi yang melibatkan fasa hot liquid water sehingga perlu dilakukan modifikasi zeolit untuk stabil pada kondisi tersebut. Sintesis zeolit HY induk dan hidrofobik bertujuan untuk mengetahui kestabilan zeolit terhadap hot liquid water (HLW). Kestabilan zeolit terhadap HLW berkaitan dengan hidrofobisitas zeolit. Pada penelitian ini, bahan baku utama sintesis zeolit $\mathrm{Y}$ induk yaitu sodium aluminat $\left(\mathrm{NaAlO}_{2}\right)$ dan Ludox HS-40 dengan proses kalsinasi produk pada temperatur $350{ }^{\circ} \mathrm{C}$ selama 1 jam. Selanjutnya, peningkatan sifat hidrofobisitas zeolit induk dilakukan dengan memodifikasi permukaan eksternal zeolit menggunakan organosilan berupa APTES (aminopropiltrietoksisilan). Kemudian dilakukan uji kestabilan kedua zeolit (induk dan modifikasi) terhadap HLW pada temperatur $200^{\circ} \mathrm{C}$. Analisis produk zeolit menggunakan uji fisik dan Fourier Transform-Infra Red (FTIR) Spektrometer. Hasil distribusi zeolit pada dua fasa memperlihatkan bahwa zeolit $\mathrm{HY}$ induk terdispersi menyeluruh pada fasa air, sedangkan pada $\mathrm{HY}$ hidrofobik terdispersi pada fasa organik. Lebih lanjut, spektrum IR zeolit HY induk menunjukkan adanya puncak semakin melebar dan titik puncak di bilangan gelombang $720 \mathrm{~cm}^{-1}$ mulai menghilang. Hal tersebut menunjukkan bahwa uji HLW mengakibatkan unit pembangun d6r mengalami kerusakan. Sebaliknya, HY hidrofobik memiliki kestabilan termal yang terlihat dari puncak-puncak pita serapan selama 72 jam. Hal tersebut mengindikasikan bahwa HY hidrofobik memiliki kestabilan termal terhadap HLW sehingga dapat digunakan dalam aplikasi katalitik reaksi kimia yang menggunakan fasa tersebut.
\end{abstract}

Kata kunci: hidrofobisitas, zeolit HY, organosilan, hot liquid water

\begin{abstract}
Initially, zeolite catalysts cannot be used for reactions involving hot liquid water, so it is necessary to modify the zeolite to be stable under these conditions. The synthesis of HY and hydrophobic zeolites aimed to determine the stability of zeolite in hot liquid water (HLW). The stability of zeolite in HLW is related to zeolite hydrophobicity. In this study, the main raw materials for the synthesis of HY zeolite were sodium aluminate $\left(\mathrm{NaAlO}_{2}\right)$ and Ludox $\mathrm{HS}-40$ by calcining the product at $350{ }^{\circ} \mathrm{C}$ for 1 hour. Furthermore, increasing the hydrophobicity of HY zeolite was carried out by modifying the external zeolite surface using organosilanes (aminopropyltriethoxysilane). The stability of two zeolites in HLW was set at $200{ }^{\circ} \mathrm{C}$. Zeolite analysis used physical test and Fourier Transform-Infra Red (FTIR) Spectrometer. The results of the zeolite distribution in two phases confirmed that HY zeolite was completely dispersed in the water phase, while the zeolite one was dispersed in the organic phase. Moreover, the IR spectra of HY zeolite showed that the wide peak detection at wave number $720 \mathrm{~cm}^{-1}$ for beginning to disappear. This means that the HLW condition could be damaged to the d6r unit. Another result was shown by hydrophobic zeolite spectra with a stable peak for 72 hours. This indicates that the hydrophobic zeolite has thermal stability in HLW so that it can be used in chemical reaction catalytic applications that use on phase.
\end{abstract}

Keywords: hydrophobicity, HY zeolite, organosilane, hot liquid water

\section{Pendahuluan}

Zeolit merupakan senyawa yang memiliki pori-pori berukuran molekuler sehingga dapat digunakan sebagai katalis, pertukaran ion, penyaringan (sieving), dan adsorben [1]. Zeolit terdiri dari kerangka 3 dimensi dan mikropori berukuran (3-15 ̊). Secara umum, struktur zeolit adalah suatu polimer anorganik berbentuk tetrahedral 
unit $\mathrm{TO}_{4}$, dimana $\mathrm{T}$ adalah ion $\mathrm{Si}^{4+}$ atau $\mathrm{Al}^{3+}$ yang saling berhubungan melalui atom $O$ [2]. Dalam perkembangannya, zeolit sintetis banyak dimanfaatkan daripada zeolit alam. Adanya logamlogam sebagai zat pengotor pada zeolit alam mempengaruhi kemurnian pada senyawa sehingga perlu dilakukan modifikasi dan aktivasi terlebih dahulu. Lebih lanjut, zeolit mempunyai sifat dehidrasi apabila dipanaskan karena bersifat polar. Hal ini menyebabkan kerangka zeolit akan menyusut atau mengalami kerusakan, akan tetapi kerangka dasar pada umumnya tidak mengalami perubahan secara nyata [3].

Salah satu zeolit sintesis dengan tipe kerangka Faujasite (FAU) yaitu zeolit HY. Karakterisasi dari zeolit HY memiliki rasio Si/Al 3-6 [4] dan ukuran pori $7,4 \AA$ [5]. Zeolit dengan tipe Faujasite telah banyak digunakan pada industri pemisahan dan proses adsorpsi (contoh: penghilangan polutan, pengolahan air, dan lain-lain) serta katalis (contoh: fluid catalytic cracking, reaksi konversi biomassa) [6]. Katalis zeolit ternyata efisien diterapkan pada konversi biomassa menjadi bio-energi [7]. Proses konversi umumnya menggunakan fasa gas karena beroperasi pada temperatur tinggi. Hal tersebut terbukti cukup banyak pengolahan biomassa lignoselulosa dalam fasa uap sebagai kondisi operasi [8]. Akan tetapi fasa gas dalam penerapannya membutuhkan biaya cukup tinggi dan instalasi alat yang cukup rumit. Dalam beberapa tahun terakhir, penelitian melaporkan adanya pemilihan fasa aqueous untuk reaksi tertentu yang dapat melibatkan zeolit. Fasa aqueous dipilih karena biaya operasional yang relatif murah, kemampuan yang tinggi untuk melarutkan produk biomassa teroksigenasi, dan ramah lingkungan [8] [9]. Reaksi konversi biomassa pada fasa aqueous dengan temperatur rendah antara lain isomerisasi atau dehidrasi monosakarida pada $179,85{ }^{\circ} \mathrm{C}$ [10] dan hidrolisis selulosa dengan temperatur $150-100{ }^{\circ} \mathrm{C}$ [11]. Namun, salah satu faktor yang dapat mempengaruhi kinerja zeolit pada fasa aqueous adalah desilikasi yang dapat menurunkan aktivitas katalitik pada kondisi operasi tertentu [12] [13]. Pengaruh aktivitas katalitik pada fase aqueous yang lain adalah kemungkinan terjadinya degradasi katalis oleh efek korosif ion $\mathrm{H}^{+}$ atau $\mathrm{OH}^{-}$dan karbon organik terlarut dalam air apabila apabila beroperasi pada temperatur tinggi [14]. Hal ini mengindikasikan bahwa stabilitas zeolit yang kurang efektif terhadap hot liquid water (HLW). Menurut penelitian Ravenel et al. (2011) menyatakan adanya peningkatan stabilitas katalis heterogen di fase aqueous dapat melalui modifikasi permukaan zeolit, coating film tipis, atau dengan modifikasi lain [15]. Selain itu, menaikkan rasio $\mathrm{Si} / \mathrm{Al}$ dapat meningkatkan sifat hidrofobik zeolit, akan tetapi metode ini dapat mengurangi densitas asam Brønsted pada zeolit dan mengakibatkan penurunan aktivitas katalitik [12] [16].
Peningkatan stabilitas zeolit dapat dilakukan dengan meningkatkan hidrofobisitas zeolit. Sifat hidrofobik dengan modifikasi permukaan eksternal zeolit menggunakan organosilan. Penelitian terdahulu oleh Zapata et al. (2012) menganalisis sifat hidrofobik zeolit komersil USY dengan rantai panjang alkyltrichlorosilane [8]. Kemudian diikuti penelitian lain yaitu zeolit BEA dimodifikasi dengan trimethylchlorosilane (TMS-Cl) dan menghasilkan stabilitas zeolit terhadap HLW di temperatur $300{ }^{\circ} \mathrm{C}$ [17]. Lebih lanjut, peningkatan hidrofobisitas zeolit jenis lain berupa ZSM-5 dan MOR dengan organosilan juga berhasil dilakukan. Modifikasi zeolit MOR dengan organosilan APTES dapat meningkatkan kestabilan zeolit MOR terhadap HLW pada temperatur $200{ }^{\circ} \mathrm{C} \quad$ [18]. Hal tersebut menunjukkan bahwa zeolit yang dimodifikasi dengan organosilan memiliki sifat yang stabil terhadap HLW sehingga dapat digunakan sebagai katalis konversi biomassa pada sistem aqueous phase. Dari uraian diatas, maka pada penelitian ini adalah pengaruh sintesis zeolit HY dengan modifikasi organosilan untuk meningkatkan hidrofobisitas zeolit HY dan kemudian karakterisasi produk menggunakan uji fisik distribusi zeolit pada dua fasa (air-organik) dan ATR-IR.

\section{Metodologi Penelitian \\ Bahan Kimia/Materials}

Bahan-bahan yang digunakan pada penelitian ini adalah $\mathrm{NaAlO}_{2}$ (Sigma-Aldrich), Ludox HS-40 (Sigma-Aldrich), $\mathrm{NaOH}$ pellet (Merck), $\mathrm{NH}_{4} \mathrm{Cl}$ (Merck), 3- aminopropiltrietoksisilan atau APTES (Sigma-Aldrich), etanol, toluena, kertas saring, alumunium foil dan Aqua DM.

\section{Peralatan}

Alat-alat yang digunakan dalam penelitian ini adalah gelas kimia, batang pengaduk, kaca arloji, pipet tetes, spatula, gelas ukur $100 \mathrm{~mL}$, cawan penguap, pengaduk magnetik, botol polipropilen, tabung Teflon, autoklaf, tanur, neraca analitik, corong Buchner, pompa vakum, pipet mikro skala 100-1000 $\mu \mathrm{L}$, oven, dan lempeng pemanas. Peralatan tambahan yang digunakan untuk tahap analisis gugus fungsi yaitu Fourier Transform-Infra Red (FTIR).

\section{Prosedur Penelitian}

Prosedur secara umum sintesis zeolit $\mathrm{NaY}$ induk, protonasi zeolit $\mathrm{NaY}$ menjadi zeolit $\mathrm{HY}$, modifikasi zeolit HY dengan organosilan, dan uji hot liquid water (HLW) antara zeolit HY induk (tanpa modifikasi) dan modifikasi zeolit $\mathrm{HY}$ dengan organosilan (HY hidrofobik). Hasil sintesis zeolit HY induk dan hidrofobik dirakterisasi menggunakan uji distribusi fisik pada dua fasa (air-organik) dan analisis ATR-IR

\section{Sintesis Zeolit}

Zeolit $\mathrm{NaY}$ disintesis dengan perbandingan komposisi molar $13 \quad \mathrm{Na}_{2} \mathrm{O}: 1 \quad \mathrm{Al}_{2} \mathrm{O}_{3}: 28,2 \quad \mathrm{SiO}_{2}: 471$ 
$\mathrm{H}_{2}$ O. Sintesis dimulai dengan melarutkan $12,74 \mathrm{~g}$ $\mathrm{NaOH} 50 \%$ (w/v) dalam 30,29 g akuades ke dalam botol polipropilen $100 \mathrm{~mL}$. Lalu sebanyak 1,01 g $\mathrm{NaAlO}_{2}$ dan 26,11 g Ludox HS-40 ditambahkan ke dalam campuran tersebut. Hasil sintesis ini diberi nama $\mathrm{NaY}$ induk. Kemudian, protonasi zeolit $\mathrm{NaY}$ dilakukan dengan mereaksikan $2 \mathrm{~g}$ zeolit $\mathrm{NaY}$ dalam $100 \mathrm{~mL} \mathrm{NH} \mathrm{NCl}_{4}$ 0,1 M kemudian diaduk dengan pengaduk magnetik dan dipanaskan pada temperatur $80{ }^{\circ} \mathrm{C}$ selama 6 jam. Setelah pengadukan, campuran disaring, dikeringkan, dan kemudian dikalsinasi pada temperatur $350{ }^{\circ} \mathrm{C}$ selama 1 jam. Sampel ini merupakan zeolit HY induk tanpa modifikasi. Selanjutnya, untuk variabel pembanding yaitu modifikasi zeolit HY dengan dilarutkan $1 \mathrm{~g}$ dalam 20 $\mathrm{mL}$ toluena dan disonikasi. Kemudian ditambahkan $50 \mathrm{~mL}$ organosilan (3-aminopropiltrietoksisilan) Campuran tersebut diaduk dengan pengaduk magnetic $500 \mathrm{rpm}$ selama 24 jam pada temperatur ruang. Setelah pengadukan selesai, campuran disaring dan dicuci beberapa kali dengan etanol sampai $\mathrm{pH}$ netral. Padatan yang diperoleh lalu dikeringkan pada temperatur $100{ }^{\circ} \mathrm{C}$ selama 24 jam dan sampel ini diberi nama zeolit HY hidrofobik. Zeolit HY induk dan HY hidrofobik kemudian diuji terhadap hot liquid water (HLW) di dalam autoclave dengan variasi waktu uji yaitu 0,$5 ; 1,2,4,10$, dan 72 jam pada temperatur $200{ }^{\circ} \mathrm{C}$ dan tekanan atmosferik.

\section{Pengukuran}

Zeolit HY induk dan hidrofobik didistribusikan pada dua fasa yaitu fasa air dan fasa organik. Pelarut nonpolar yang digunakan sebagai fasa organik yaitu toluena. Masing-masing zeolit dimasukkan ke dalam botol vial yang telah terisi fasa air dan organik. Kemudian diamati hasil yang terjadi. Analisis ATR-IR yang dilakukan menggunakan Bruker Alpha FTIR Spectrometer pada temperatur ruang dengan resolusi spektra sebesar $4 \mathrm{~cm}^{-1}$ dan scan time 512. Panjang gelombang yang diukur dari $500 \mathrm{~cm}^{-1}$ sampai $4000 \mathrm{~cm}^{-1}$. Data yang ditampilkan berupa spektrum bilangan gelombang $\left(\mathrm{cm}^{-1}\right)$ dan absorban yang kemudian dialurkan menjadi pola spektrum.

\section{Hasil}

Sintesis awal zeolit HY induk dan HY hidrofobik

Dari hasil uji fisik pada Gambar 1, distribusi zeolit dalam dua fasa yaitu fasa air dan organik yang diketahui sebagai keberhasilan modifikasi zeolit dengan organosilan. Uji fisik ini merupakan tahap awal sebelum karakterisasi yang lain. Fasa organik yang digunakan adalah pelarut toluena.

Pada gambar tersebut dapat diamati bahwa ada perbedaan yang jelas dalam perilaku zeolit HY induk dan hidrofobik. Zeolit HY induk terdispersi sempurna dalam fasa air, sedangkan pada zeolit hidrofobik terdispersi dalam fasa organik. Dari hasil uji fisik dapat dibuktikan bahwa modifikasi senyawa organosilan dapat meningkatkan hidrofobisitas zeolit.

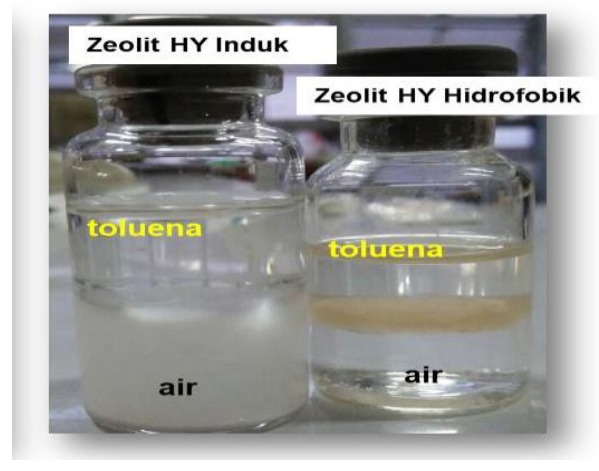

\section{Gambar 1. Distribusi zeolit pada dua fasa}

Analisis dengan spektroskopi inframerah dalam penelitian ini bertujuan untuk mempelajari perubahan gugus fungsional pada zeolit HY induk dan HY hidrofobik. Spektra berbentuk pita-pita serapan, kemudian letak pita serapan dalam spektra IR dinyatakan dengan bilangan gelombang $\left(\mathrm{cm}^{-1}\right)$, sedangkan intensitas pita serapan dinyatakan dengan persen transmitansi (\%T). Pada spektra IR yang ditunjukkan oleh Gambar 2, vibrasi tekuk hidrokarbon $(\mathrm{C}-\mathrm{H}) \quad s p^{3}$ HY hidrofobik sebagai senyawa organik teramati pada bilangan gelombang 2800-3000 $\mathrm{cm}^{-1}$. Namun puncak transmitan tersebut sangat lemah, hal tersebut disebabkan dominasi puncak transmitan khas zeolit yang sangat tinggi dan jumlah senyawa organik yang relatif sedikit. Vibrasi tekuk hidrokarbon tersebut tidak ditemukan pada zeolit HY induk. Kemudian pada bilangan gelombang $1030 \mathrm{~cm}^{-1}$ (ulur $\mathrm{Si}-\mathrm{O}-\mathrm{Si}$ ) merupakan rentang asimetri yang khas sebagai daerah serapan infra merah zeolit H-Y [19]. Selain itu, puncak transmitan pada bilangan gelombang $720-790 \mathrm{~cm}^{-1}$ terkait dengan adanya vibrasi symmetric stretching dari 4-membered rings.

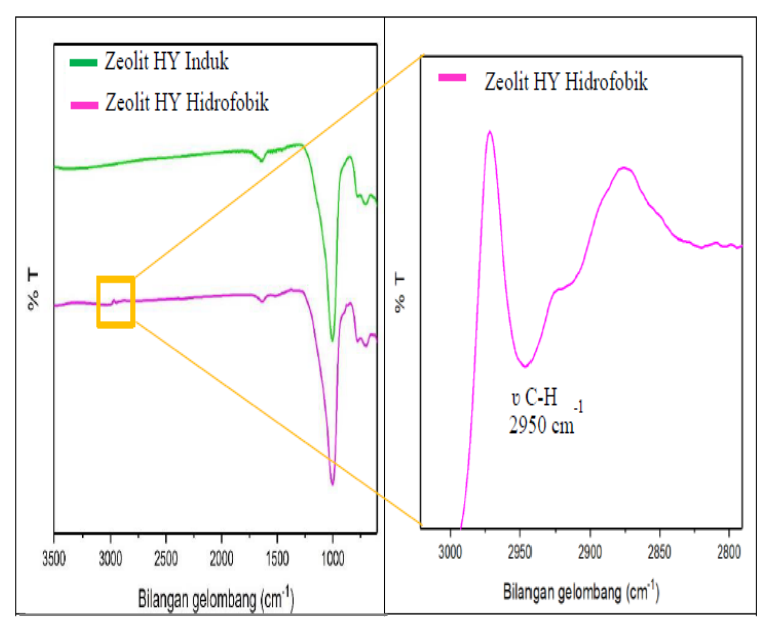

Gambar 2. Spektra IR zeolit induk dan HY hidrofobik

\section{Hasil uji Hot Liquid Water (HLW)}

Pada spektra ATR-IR, adanya vibrasi pada bilangan gelombang 720-790 $\mathrm{cm}^{-1}$ mengindikasikan 
vibrasi symmetric stretching dari 4-membered rings. Pada Gambar 3 dapat dilihat bahwa pada zeolit HY induk, bilangan gelombang tersebut terlihat jelas bahwa semakin bertambahnya waktu uji HLW, puncak tampak semakin melebar, dan puncak di bilangan gelombang $720 \mathrm{~cm}^{-1}$ mulai menghilang. Hal tersebut menunjukkan bahwa uji HLW mengakibatkan unit pembangun $d 6 r$ mengalami kerusakan.Vibrasi tekuk T-O-T zeolit teramati pada bilangan gelombang $900-1200 \mathrm{~cm}^{-1}$. Vibrasi ikatan T-O-T ini sangat sensitif terhadap perubahan rasio Si/Al, dilaporkan oleh Miecznikowski dan Hanuza (1987) bahwa semakin tinggi rasio $\mathrm{Si} / \mathrm{Al}$ maka puncak pita serapan akan bergeser kebilangan gelombang yang lebih tinggi (blue shift). Sebaliknya, semakin rendah rasio $\mathrm{Si} / \mathrm{Al}$ maka puncak pita serapan bergeser ke bilangan gelombang yang lebih rendah (red shift) [20]. Pada bahwa terjadi red shift setelah uji HLW. Hal tersebut menjelaskan bahwa spesies $\mathrm{Si}^{4+}$ terekstrak keluar dari kerangka zeolit. Keluarnya ekstrak $\mathrm{Si}^{4+}$ diduga merupakan gugus silanol $(\mathrm{SiOH})$ yang dapat meningkatkan laju hidrolisis dari molekul air sehingga akan menurunkan aktivitas katalitik zeolit terhadap HLW. Hal ini berhubungan dengan kemungkinan terjadinya peristiwa amorfisasi zeolit pada kondisi HLW yang disebabkan karena adanya hidrolisis ikatan Si-O-Si [21]. Sebaliknya, zeolit HY hidrofobik memiliki kestabilan termal yang terlihat dari puncak-puncak pita serapan selama 72 jam. Kestabilan termal tersebut berkaitan dengan penelitian Prodinger et al. (2016) bahwa cara kerja organosilan dalam melindungi zeolit yaitu dengan melindungi gugus silanol $(\mathrm{SiOH})$ yang bersifat hidrofilik pada permukaan zeolit [17].

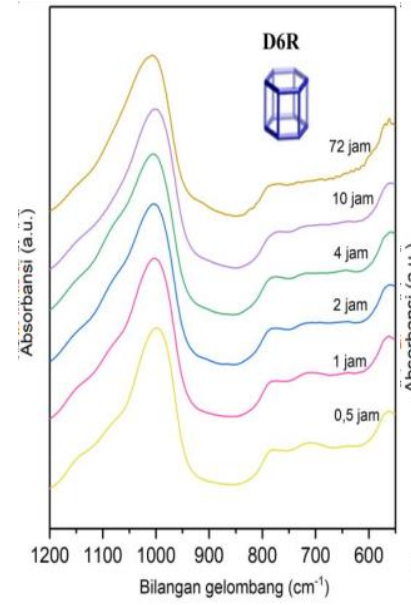

(a)

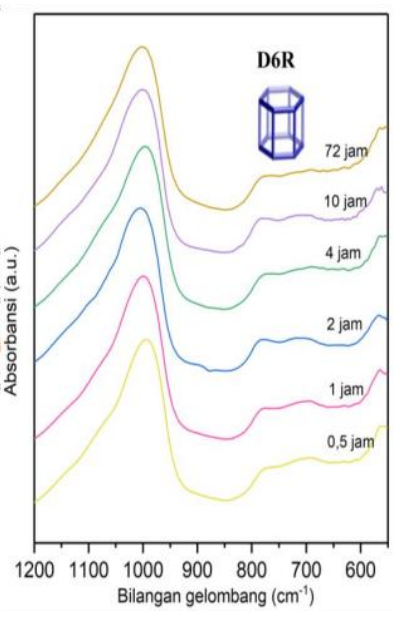

(b)
Gambar 3. Spektra IR pasca uji HLW (a) zeolit HY Induk (b) HY Hidrofobik

\section{Kesimpulan}

Pada penelitian ini telah berhasil dilakukan sistesis zeolit HY hidrofobik dengan modifikasi permukaan eksternal zeolit HY menggunakan senyawa organosilan APTES. Berdasarkan karakterisasi uji fisik zeolit $\mathrm{HY}$ induk terlarut sempurna di dalam air, kemudian HY hidrofobik dapat terdispersi pada toluena sehingga membuktikan bahwa zeolit dapat bertahan dalam fasa HLW. Selain itu, regenerasi zeolit pada fasa cair membutuhkan temperatur yang rendah sehingga biaya operasional akan lebih murah. Selanjutnya, hasil spektra IR pada zeolit HY induk memiliki kestabilan yang rendah terhadap uji HLW dibuktikan dengan hilangnya titik puncak ketika berada di panjang gelombang $720 \mathrm{~cm}^{-1}$ selama 72 jam. Hal tersebut mengindikasikan kerusakan yang terjadi pada zeolit HY induk. Hasil berbeda pada zeolit hidrofobik, dimana zeolit tersebut memiliki kestabilan termal terhadap HLW. Hal tersebut ditunjukkan dengan terlihatnya puncak transmittan pada zeolit hidrofobik selama 72 jam. Selanjutnya, penelitian ini diharapkan dapat diaplikasikan sebagai katalitik reaksi kimia yang melibatkan fasa hot liquid water.

\section{Ucapan Terima Kasih}

Penulis menyampaikan ucapan terimakasih kepada Institut Teknologi Bandung (ITB), khususnya Program Studi Kimia FPMIPA ITB dan Laboratorium Kimia Anorganik sebagai tempat pelaksanaan penelitian.

\section{Daftar Pustaka}

[1] M. Ghiaci, R. Kia, A. Abbaspur, and F. Seyedeyn-Azad, "Adsorption of chromate by surfactant-modified zeolites and MCM-41 molecular sieve," Sep. Purif. Technol., vol. 40, no. 3, pp. 285-295, 2004.

[2] D. Barlokova, "Natural Zeolites in the Water Treatment Process," Slovak J. Civ. Eng., pp. 8-12, 2008.

[3] F. M. Mahaddilla and A. Putra, "Pemanfaatan Batu Apung sebagai Sumber Silika Dalam Pembuatan Zeolit Sintetis," J. Fis. Unand, vol. 2, pp. 262-268, 2013.

[4] Z. Wang, I. Kumakiri, K. Tanaka, X. Chen, and H. Kita, "NaY zeolite membranes with high performance prepared by a variabletemperature synthesis," Microporous Mesoporous Mater., vol. 182, pp. 250-258, 2013.

[5] P. Guo, N. Yan, L. Wang, and X. Zou, "Database mining of zeolite structures," Cryst. Growth Des., vol. 17, no. 12, pp. 6821-6835, 2017.

[6] N. R. Shiju and V. V. Guliants, "Recent developments in catalysis using nanostructured materials," Appl. Catal. A Gen., vol. 356, no. 1, pp. 1-17, 2009.

[7] Y.-T. Cheng, Z. Wang, C. J. Gilbert, W. Fan, and G. W. Huber, " Production of p -Xylene from Biomass by Catalytic Fast Pyrolysis Using ZSM-5 Catalysts with Reduced Pore Openings ," Angew. Chemie, vol. 124, no. 44, pp. 11259-11262, 2012. 
[8] P. A. Zapata, J. Faria, M. P. Ruiz, R. E. Jentoft, and D. E. Resasco, "Hydrophobic Zeolites for Biofuel Upgrading Reactions at the Liquid-Liquid Interface in Water/Oil Emulsions," J. Am. Chem. Soc., vol. 134, no. 20, pp. 8570-8578, May 2012.

[9] L. Zhang, K. Chen, B. Chen, J. L. White, and D. E. Resasco, "Factors that Determine Zeolite Stability in Hot Liquid Water," $J$. Am. Chem. Soc., vol. 137, no. 36, pp. 1181011819, 2015.

[10] Y. Román-Leshkov, J. N. Chheda, and J. A. Dumesic, "Phase modifiers promote efficient production of hydroxymethylfurfural from fructose," Science (80-. )., vol. 312, no. 5782, pp. 1933-1937, 2006.

[11] C. Luo, S. Wang, and H. Liu, "Cellulose conversion into polyols catalyzed by reversibly formed acids and supported ruthenium clusters in hot water," Angew. Chemie - Int. Ed., vol. 46, no. 40, pp. 76367639, 2007.

[12] H. Xiong, H. N. Pham, and A. K. Datye, "Hydrothermally stable heterogeneous catalysts for conversion of biorenewables," Green Chem., vol. 16, no. 11, pp. 46274643, 2014.

[13] S. Eckstein, P. H. Hintermeier, M. V. Olarte, Y. Liu, E. Baráth, and J. A. Lercher, "Elementary steps and reaction pathways in the aqueous phase alkylation of phenol with ethanol," J. Catal., vol. 352, pp. 329-336, Aug. 2017.

[14] Y. Han, C. Liu, J. Horita, and W. Yan, "Trichloroethene hydrodechlorination by PdFe bimetallic nanoparticles: Solute-induced catalyst deactivation analyzed by carbon isotope fractionation," Appl. Catal. B Environ., vol. 188, pp. 77-86, Jul. 2016.

[15] R. M. Ravenelle, J. R. Copeland, W. G. Kim, J. C. Crittenden, and C. Sievers, "Structural Changes of $\gamma$-Al2O3-Supported Catalysts in Hot Liquid Water," ACS Catal., vol. 1, no. 5, pp. 552-561, 2011.

[16] S. Namba, N. Hosonuma, and T. Yashima, "Catalytic application of hydrophobic properties of high-silica zeolites. I. Hydrolysis of ethyl acetate in aqueous solution," J. Catal., vol. 72, no. 1, pp. 16-20, 1981.

[17] S. Prodinger, M. A. Derewinski, A. Vjunov, S. D. Burton, I. Arslan, and J. A. Lercher, "Improving Stability of Zeolites in Aqueous Phase via Selective Removal of Structural Defects," J. Am. Chem. Soc., vol. 138, no. 13, pp. 4408-4415, Apr. 2016.

[18] U. Khalil, O. Muraza, and A. Al-Amer, "Development of surface modified mordenite catalysts and their stability in hot liquid water," Adv. Powder Technol., vol. 27, no. 4, pp. 1404-1410, 2016.

[19] R. Silverstein, G. Bassler, and T. Morrill, "No Title," in Spectrometric Identification of Organic Compounds, 4th ed., New York: Wiley, 1981.

[20] A. Miecznikowski and J. Hanuza, "Infrared and Raman studies of ZSM-5 and silicalite-1 at room, liquid nitrogen and helium temperatures," Zeolites, vol. 7, no. 3, pp. 249-254, 1987.

[21] R. M. Ravenelle et al., "Stability of zeolites in hot liquid water," J. Phys. Chem. C, vol. 114, no. 46, pp. 19582-19595, 2010. 